\title{
Be aware of acute kidney injury in critically ill children with COVID-19
}

\author{
Xiaowen Wang ${ }^{1} \cdot$ Xingfeng Chen ${ }^{2} \cdot$ Feng Tang $^{3} \cdot$ Wanjun Luo $^{4} \cdot$ Jian Fang ${ }^{1} \cdot$ Chang $\mathrm{Qi}^{1} \cdot$ Hua Sun $^{5} \cdot$ Han Xiao $^{6}$. \\ Xuehua Peng ${ }^{7} \cdot$ Jianbo Shao ${ }^{2,7,8}$
}

Received: 23 April 2020 / Revised: 19 June 2020 / Accepted: 13 July 2020 / Published online: 26 August 2020

(C) IPNA 2020

\begin{abstract}
Background Acute kidney injury (AKI) is a common complication of critically ill adult patients with COVID-19. However, currently, no studies investigate kidney impairment in children with COVID-19. We investigated incidence and treatment of AKI in pediatric patients with COVID-19 in Wuhan Children's Hospital during the early stages of the COVID-19 pandemic and discuss possible mechanisms of AKI related to SARS-CoV-2 infection.

Methods By extracting data from electronic medical records, we conducted a retrospective observational study of kidney involvement in confirmed pediatric COVID-19 cases in Wuhan Children's Hospital during the coronavirus outbreak, from January 24 to March 20, 2020. Clinical presentations, clinical courses, laboratory findings, and medical interventions are described below.

Results Among 238 confirmed COVID-19 cases, only three were critically ill and needed intensive care unit (ICU) admission. All three developed AKI, but AKI was not detected in any non-critically ill patients outside the ICU. Two of the three patients with AKI had prodromal gastrointestinal symptoms. Significantly elevated interleukin-6 (IL-6) levels and complement activation were observed in these patients with AKI. The three patients with AKI were treated with plasma exchange (PE) and continuous kidney replacement therapy (CKRT), resulting in one complete recovery, one partial recovery, and one mortality due to critical illness.

Conclusions Critically ill children with COVID-19 may develop AKI, especially following prodromal gastrointestinal symptoms. An inflammatory storm and complement-mediated injury may underlie AKI development in children with COVID-19. Our study supports implantation of PE and CKRT in management of critically ill patients with AKI.
\end{abstract}

Keywords COVID-19 · AKI · Plasmapheresis · CKRT

Xiaowen Wang and Xingfeng Chen contributed equally to this work.

Jianbo Shao

shaojb2002@sina.com

1 Department of Nephrology, Wuhan Children's Hospital (Wuhan Maternal and Child Healthcare Hospital), Tongji Medical College, Huazhong University of Science \& Technology, Wuhan 430000, China

2 Intensive Care Unit, Wuhan Children's Hospital (Wuhan Maternal and Child Healthcare Hospital), Tongji Medical College, Huazhong University of Science \& Technology, Wuhan 430000, China

3 Department of Laboratory Medicine, Wuhan Children's Hospital (Wuhan Maternal and Child Healthcare Hospital), Tongji Medical College, Huazhong University of Science \& Technology, Wuhan 430000, China

4 Hospital Acquired Infection Control Department, Wuhan Children's Hospital (Wuhan Maternal and Child Healthcare Hospital), Tongji Medical College, Huazhong University of Science \& Technology, Wuhan 430000, China
5 Department of Nephrology, Boston Children's Hospital, Harvard Medical School, Boston, MA 02115, USA

6 Institute of Maternal and Child Health, Wuhan Children's Hospital (Wuhan Maternal and Child Healthcare Hospital), Tongji Medical College, Huazhong University of Science \& Technology, Wuhan 430000, China

7 Medical Imaging Center, Wuhan Children's Hospital (Wuhan Maternal and Child Healthcare Hospital), Tongji Medical College, Huazhong University of Science \& Technology, Wuhan 430000, China

8 Institute of Maternal and Child Health, Wuhan Children's Hospital (Wuhan Maternal and Child Healthcare Hospital), 100\# Hongkong Road, Wuhan 430000, China 


\section{Introduction}

Coronavirus disease 2019 (COVID-19), a novel illness caused by severe acute respiratory syndrome coronavirus 2 (SARSCoV-2), was initially discovered in Wuhan in 2019 and has now resulted in a global pandemic. As of April 18, 2020, there have been more than 80,000 confirmed cases in China, $60 \%$ of which were reported in Wuhan. According to the World Health Organization, the number of global cases has reached 2,000,000 with over 150,000 deaths. Although the virus primarily targets the lungs, disease manifestation is common in other organ systems. A study of SARS showed that $6.7 \%$ of patients developed acute kidney injury (AKI), with a mortality of $91.7 \%$ [1]. Clinicopathological studies have demonstrated that the kidneys are another target of SARS-CoV-2. Notably, AKI is a common complication of critically ill adult patients with COVID-19, with an incidence ranging from 5.1 to $29 \%$. AKI is strongly associated with the mortality of COVID-19, especially in the ICU [2-5]. However, there have not yet been studies of kidney involvement in children with COVID-19.

A review of 72,314 cases by the Chinese Center for Disease Control and Prevention (CCDC) revealed that pediatric cases account for $1 \%$ of the total COVID-19 cases [6]. A study of 171 children infected with SARS-CoV-2 showed that most children had a milder clinical course compared to adults, but there were also rare severe cases [7]. To explore the clinical features of AKI in children with COVID-19, we evaluated 238 confirmed cases in Wuhan Children's Hospital, the center assigned by the CCDC for the care of infected children younger than 16 years of age in Wuhan. Among these cases, only three patients were critically ill and needed care in the ICU, and all of them developed AKI, suggesting that AKI is an important factor that defines the severity and the progression of the disease.

To better understand AKI in severe pediatric cases with COVID-19, we studied the clinical characteristics, laboratory and imaging features, treatments, and outcomes of the three children with COVID-19 complicated with AKI.

\section{Methods}

\section{Patients and data collection}

A total of 238 cases of COVID-19 admitted to Wuhan Children's Hospital from January 24th to March 20th were enrolled in the retrograde observational study. Wuhan Children's Hospital is the local center assigned by the CCDC for the care of the infected children younger than 16 years of age. All the patients were confirmed with SARS-CoV-2 infection by real-time reverse transcription-polymerase chain reaction (RT-PCR) assay using nasopharyngeal $(<2$ years) or throat $(>2$ years) swab specimens. We examined their kidney function test, including serum BUN and creatinine, and calculated their estimated glomerular filtration rate (eGFR) using the Schwartz equation [8]. Demographic characteristics, clinical presentations, and radiology and laboratory features, as well as medications, were extracted from electronic medical records.

\section{Definition}

Critically ill COVID-19 was defined as patients who met any of the following criteria: (1) respiratory failure which required mechanical ventilation; (2) septic shock; and (3) accompanied by failure of other organs that required ICU monitoring and treatment [7].

Acute kidney injury was defined as an increase of serum creatinine by $0.3 \mathrm{mg} / \mathrm{dL}(26.4 \mathrm{mmol} / \mathrm{L})$ within $48 \mathrm{~h}$ or a $50 \%$ increase in serum creatinine from baseline within 7 days according to the Kidney Diseases Improving Global Outcomes (KDIGO) clinical practice guidelines [9]. The stage of AKI was determined using the peak serum creatinine level after AKI detection, with increases of 1.5-1.9, 2.0-2.9, and $\geq 3$ times baseline being defined as AKI stage 1, 2, and 3, respectively. Absolute increase of creatinine and decreased urine output were also taken into consideration [10].

\section{Results}

\section{Clinical presentations}

Three out of 238 patients with COVID-19 were critically ill and required ICU care, and all of them met the criteria of AKI: AKI was not detected in any patients outside of the ICU. Table 1 lists the clinical features of the three ICU patients with COVID-19. Two previously healthy infants, patient 1 (13 months old) and 2 (10 months old), developed oliguric AKI with prodromal gastrointestinal symptoms, including vomiting and diarrhea. The younger patient of 10 months of age also developed intussusception. Patient 3, an 8-year-old boy, was an immunocompromised patient with acute lymphocytic leukemia (ALL) and received chemotherapy. All of them presented with fever and developed dyspnea, while only patient 3 presented with cough.

\section{Laboratory findings}

The lab tests revealed lymphopenia, anemia, and thrombocytopenia in the three patients. The results of the blood cell count of the first day and the most severe values are listed in Table 1. Acute phase reactants including high-sensitivity $\mathrm{C}$-reactive protein $(\mathrm{CRP})$, procalcitonin $(\mathrm{PCT})$, and interleukin-6 (IL-6) were significantly increased in all three patients (Table 1). The IL-6 level of patient 2 significantly increased $(3800 \mathrm{pg} / \mathrm{mL}, 200$-fold above normal range), corresponding to the peak of his creatinine. The trend of IL-6 and serum creatinine in the three patients are plotted in 
Table 1 Clinical features of 3 AKI patients with COVID-19

\begin{tabular}{|c|c|c|c|}
\hline Patient number & 1 & 2 & 3 \\
\hline Age & 13 months & 10 months & 8 years \\
\hline Gender & Male & Female & Male \\
\hline Exposure history & No & Suspected & No \\
\hline Days from illness onset to admission & 6 & 2 & 0 \\
\hline Comorbidity & No & No & ALL \\
\hline Chief complaint & Fever and diarrhea & Bloody stool and vomiting & Fever and cough \\
\hline \multicolumn{4}{|l|}{ Symptoms } \\
\hline Fever & Yes & Yes & Yes \\
\hline Cough & No & No & Yes \\
\hline Vomiting & Yes & Yes & No \\
\hline Diarrhea & Yes & Yes & No \\
\hline Decreased urine output & Oliguria & Oliguria & No \\
\hline Admission to ICU & Yes & Yes & Yes \\
\hline In-hospital duration (days) & 17 & 34 & $>60$ still in hospital \\
\hline AKI stage & 3 & 3 & 2 \\
\hline Lab (unit; normal range) & First day in ICU/most severe & First day in ICU/most severe & First day in ICU/most severe \\
\hline $\mathrm{WBC}\left(\times 10^{9} / \mathrm{L} ; 5.5-12.0\right)$ & $11.96 / 3.63$ & $5.29 / 2.87$ & $1.98 / 0.88$ \\
\hline Lymphocytes $\left(\times 10^{9} / \mathrm{L} ; 1.2-6.0\right)$ & $2.48 / 1.4$ & $3.08 / 0.2$ & $0.15 / 0.15$ \\
\hline $\mathrm{Hb}(\mathrm{g} / \mathrm{L} ; 110-149)$ & $100 / 78$ & $114 / 43$ & $78 / 70$ \\
\hline Plt $\left(\times 10^{9} / \mathrm{L} ; 100-300\right)$ & $184 / 42$ & $144 / 16$ & $71 / 49$ \\
\hline PCT (ng/mL; 0-0.046) & $0.43 / 2.66$ & $>100 />100$ & $0.2 / 4.19$ \\
\hline $\mathrm{CRP}(\mathrm{mg} / \mathrm{L} ; 0-10)$ & $24.8 / 69$ & $188 / 188$ & $8.84 / 119$ \\
\hline IL-6 (pg/mL; 0-20) & $120.31 / 177.86$ & $3868 / 3868$ & $16.14 / 639$ \\
\hline $\mathrm{C} 3(\mathrm{~g} / \mathrm{L} ; 0.7 \sim 1.12)$ & $0.66 / 0.36$ & $0.33 / 0.33$ & NA \\
\hline $\mathrm{C} 4(\mathrm{~g} / \mathrm{L} ; 0.1-0.38)$ & $0.10 / 0.07$ & $0.07 / 0.07$ & NA \\
\hline D-dimer $(\mathrm{mg} / \mathrm{L} ; 0-0.55)$ & $5.27 / 5.27$ & $40.34 / 40.34$ & NA/9.25 \\
\hline $\mathrm{LDH}(\mathrm{u} / \mathrm{L} ; 120-300)$ & $361 / 751$ & $3171 / 3171$ & $388 / 625$ \\
\hline BUN (mmol/L; 2.9-7.1) & $15.91 / 15.91$ & $22.84 / 40$ & $2.9 / 8$ \\
\hline $\operatorname{SCR}(\mu \mathrm{mol} / \mathrm{L})$ & $224 / 224$ & $206.3 / 260$ & $21.2 / 40$ \\
\hline eGFR $\left(\mathrm{mL} / \mathrm{min} / 1.73 \mathrm{~m}^{2}\right)$ & $17 / 17$ & $19 / 15$ & $>120 / 90$ \\
\hline Acidosis & Yes & Yes & No \\
\hline Proteinuria & \pm & +++ & No \\
\hline Hematuria & No & Mild & No \\
\hline \multicolumn{4}{|l|}{ Imaging features of lung (CT) } \\
\hline Ground-glass opacity & Yes & Yes & Yes \\
\hline Patchy shadowing & Yes & Yes & Yes \\
\hline Consolidation & Yes & Yes & Yes \\
\hline Pleural effusion & Yes & Yes & Yes \\
\hline Interstitial abnormalities & No & Yes & No \\
\hline \multicolumn{4}{|l|}{ Treatment } \\
\hline Ventilation & Yes & Yes & Yes \\
\hline Antibiotic & Meropenem + linezolid & Meropenem + linezolid & Meropenem + linezolid + caspofungin \\
\hline Antivirus & Oseltamivir & Ribavirin & Ribavirin + abidol \\
\hline Corticosteroids & Yes & Yes & Yes \\
\hline IVIG & Yes & Yes & Yes \\
\hline Blood purification & $\mathrm{PE}+\mathrm{CKRT}$ & $\mathrm{PE}+\mathrm{CKRT}$ & $\mathrm{PE}+\mathrm{CKRT}$ \\
\hline Outcome & Recovered & Died & Stable \\
\hline
\end{tabular}

$A L L$ acute lymphoblastic leukemia, $W B C$ white blood cell, $H b$ hemoglobin, $P l t$ platelet, $P C T$ procalcitonin, $C R P$ C-reactive protein, $I L-6$ interleukin-6, $C 3$ complement 3, $C 4$ complement 4, $L D H$ lactate dehydrogenase, $B U N$ blood urea nitrogen, $S C R$ serum creatinine, eGFR estimated glomerular filtration rate, IVIG intravenous immunoglobin, $P E$ plasma exchange, CKRT continuous kidney replacement therapy, NA not available

Fig. 1. Patient 1 and 2 developed hypocomplementemia. Lactate dehydrogenase and D-dimer were markedly elevated in all three patients. The two infants met the criteria of stage 3 AKI with significantly elevated serum creatinine and decreased eGFR. Patient 3 met the criterion of AKI stage 1 due to the doubling of serum creatinine.

\section{Imaging features}

Chest CT scan demonstrated patchy shadows, consolidation, and pleural effusion in the 3 patients (Fig. 2a-c). Ascites and enlarged kidneys were observed in the two infants (Fig. 3a, b). 


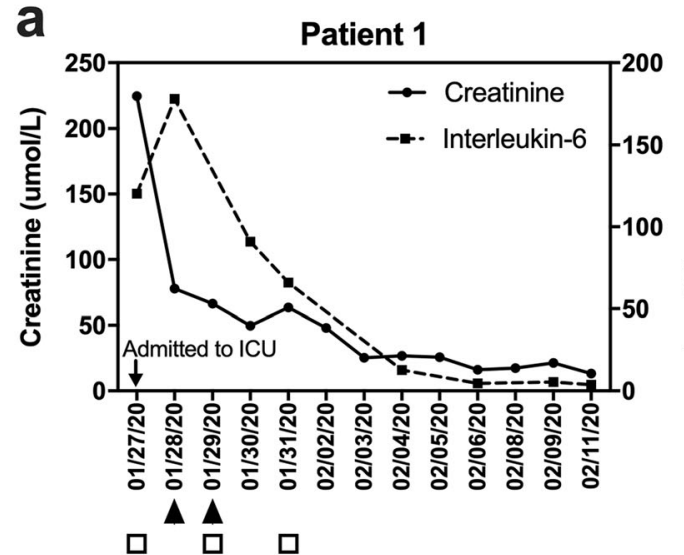

$\triangle P E \quad \square C V H D F$

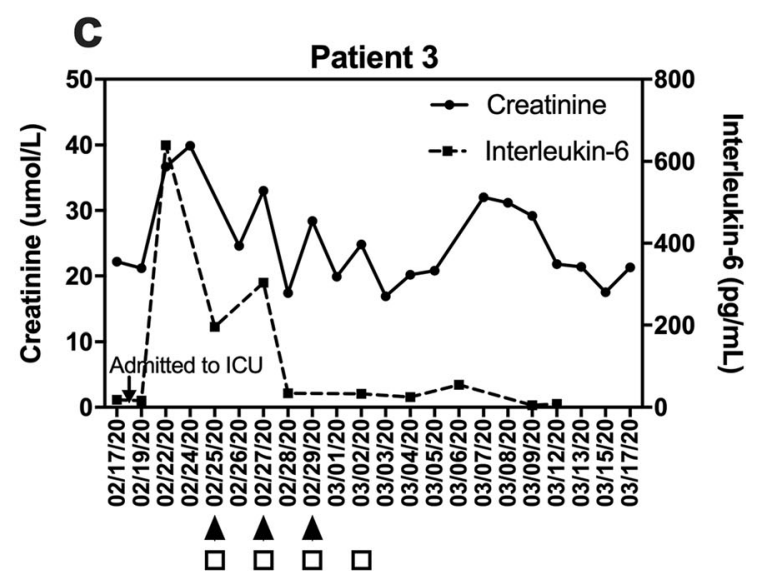

$\triangle P E \quad \square C V V H D F$

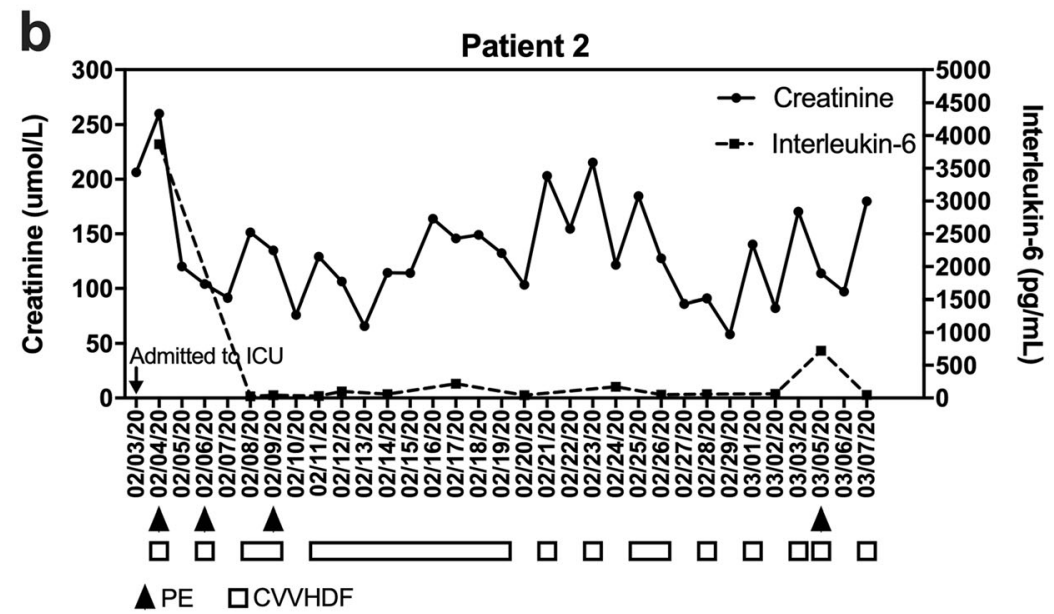

Fig. 1 Correlation of serum creatinine and IL-6 levels in patients 1 (a), 2 (b), and 3 (c). Creatinine curve, solid line; IL-6 curve, dashed line. Plasma exchange and CKRT are labeled under the timeline in triangles and

quadrilaterals, respectively. PE, plasma exchange; CVVHDF, continuous veno-venous hemodiafiltration

\section{Medical interventions}

Each of the three patients required mechanical ventilation. Empirical antibiotics, antivirals, corticosteroids, and intravenous immunoglobin were used in all three patients (see

Table 1). All three patients were also treated with plasma exchange (PE) combined with continuous kidney replacement therapy (CKRT) (Fig. 1a-c). Heparin was used for anticoagulation both in PE and CKRT. Continuous veno-venous hemodiafiltration (CVVHDF) was indicated in patient 1 and 2
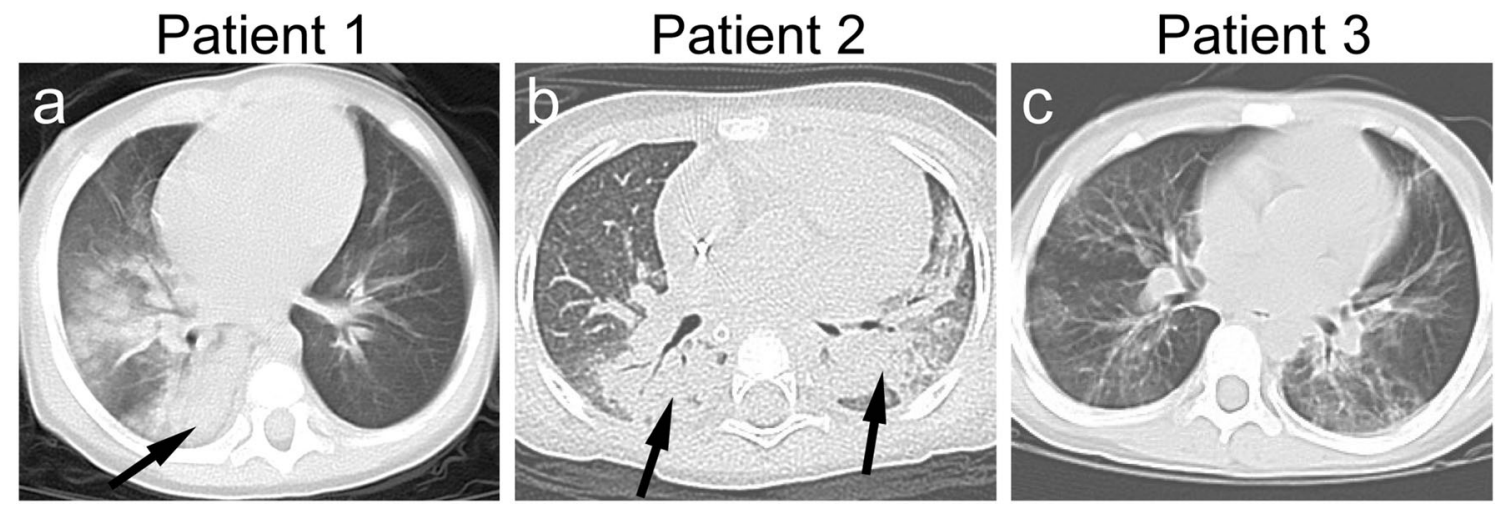

Fig. 2 Axial chest CT of the three AKI patients with COVID-19. a Consolidation of the right lung of patient 1 is indicated by the arrow; $\mathbf{b}$ consolidation of bilateral lungs of patient 2 (arrows); $\mathbf{c}$ diffused patchy shadowing of bilateral lungs of patient 3 
Fig. 3 Axial abdomen CT scan images of patients 1 and $2(\mathbf{a}, \mathbf{b})$ showing enlarged kidneys (arrows). Hydronephrosis of the left kidney can be observed in patient 1 (star). The hydronephrosis disappeared before discharge
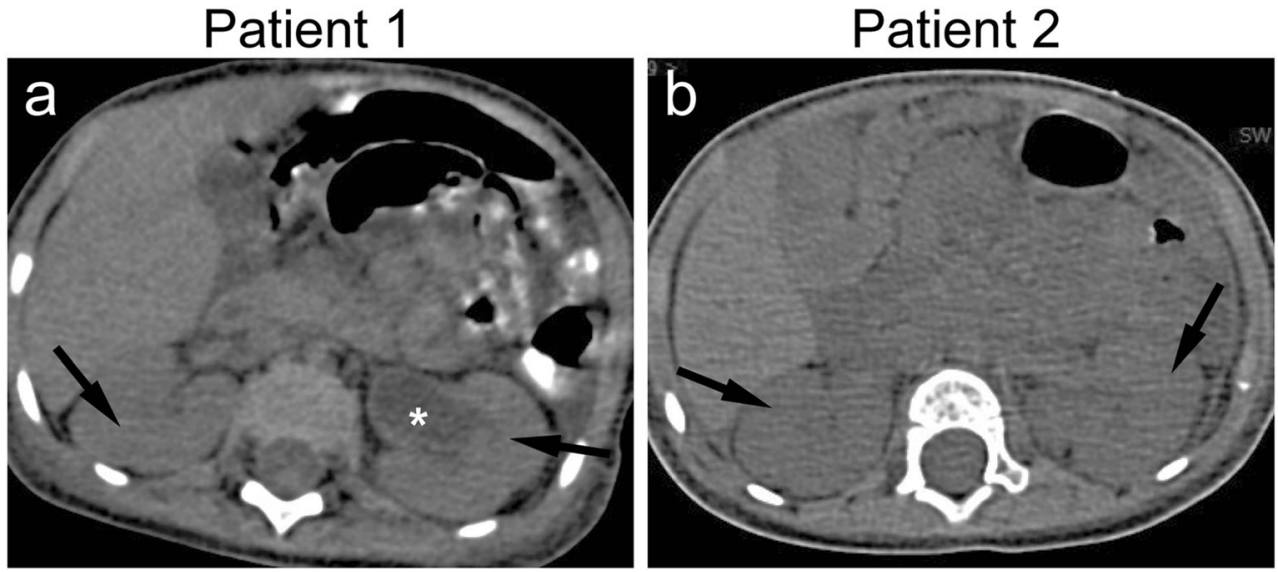

for oliguria and organ function failure, and indicated in patient 3 for AKI in the setting of significant fluid overload.

Patient 1 recovered and was discharged from the ICU after a duration of 17 days. Patient 2 passed away due to severe sepsis and intestinal necrosis secondary to intussusception, despite intensive surgical and medical interventions. Patient 3 , who presented with leukemia, was successfully weaned off ventilation and kidney replacement therapy.

\section{Discussion}

This is the first study describing AKI in pediatric patients with COVID-19. Data on internal medicine has revealed that kidney impairment is much more common in COVID-19 than in SARS $[1,11]$. The overall incidence of AKI in adult patients with COVID-19 ranges from 5.1 to $29 \%$ depending on the cohort and severity of cases [5, 12]. Comorbidities including diabetes, chronic kidney diseases, and primary hypertension are frequently seen in critically ill patients whose clinical course is complicated by AKI [13]. Data in pediatric patients has revealed a different profile of AKI with different underlying etiologies compared to adults. The AWARE (Assessment of Worldwide Acute Kidney Injury, Renal Angina, and Epidemiology) study, which enrolled ICUs in 32 hospitals in Asia, Australia, Europe, and North America, showed that the overall incidence of AKI in 4683 critically ill children was $26.9 \%$, and the incidence of severe AKI (KDIGO stage 2 or $3)$ was $11.6 \%[8,14]$. Another multi-center study reported an incidence of AKI of $20 \%$ in the total 101,836 pediatric inpatients from 25 centers in China [15], where AKI occurred in $49.1 \%$ of children with respiratory failure. In our cohort, the incidence of AKI in pediatric patients with COVID-19 was $1.2 \%(3 / 238)$, much less common than in adults. However, based on the limited cases of our study, AKI seemed to be a significant complication in critically ill children with COVID19, far more than other etiologies [16-18].
Angiotensin-converting enzyme 2 (ACE2) is the key receptor that SARS-CoV-2 uses to gain access to its target cells $[19,20]$. In addition to the lung, ACE2 is also highly expressed in the small intestine, colon, and kidney, which can explain the gastrointestinal and kidney involvement in our critically ill children with COVID-19 [21, 22]. Compared to adults, young children and especially infants are more prone to develop a gastrointestinal invasion of COVID-19, and the subsequent dehydration with hypoperfusion of kidneys significantly increases the risk of developing AKI. Both of the infants in our study with AKI stage 3 had prodromal gastrointestinal symptoms and dehydration event. One of these resulted in a significant surgical complication, suggesting that a prodromal gastrointestinal involvement may increase susceptibility of children to AKI in the setting of COVID-19. Additionally, nephrotoxic medicines, including antibiotics, antiviral treatment [16], and a calcineurin inhibitor in patient 3, were further risk factors for AKI.

Diao et al. examined the viral nucleocapsid protein in situ in the kidney postmortem and found that SARS-CoV-2 antigens accumulated in kidney tubules, suggesting that SARS-CoV-2 infects the human kidney directly and may induce AKI [4]. Further, cytokine release syndrome (CRS) has been recognized as a feature of SARS-CoV-2 infection with AKI as in SARS [12, $23,24]$. In patients with CRS, AKI could be a result of intrarenal inflammation, endothelial injury, increased vascular permeability, and volume depletion [25]. Proinflammatory IL-6 is considered to be the most important causative cytokine in CRS [26]. The correlation between IL- 6 titer and serum creatinine level in our patients suggests that cytokine storm might play a more important role in critically ill COVID-19 children with AKI, in addition to the prerenal and intrarenal injuries.

Thrombocytopenia and anemia were also observed in both of the infants, together with their increased lactate dehydrogenase, suggesting that microangiopathy can be another underlying pathophysiology of AKI, which has been well described in thrombotic microangiopathy (TMA) related to an uncontrolled complement activation [27]. In a recent study, Su et al. reported 
postmortem renal histopathological analysis of 26 patients with COVID-19, where endothelial cell swelling and segmental fibrin thrombi in glomerular capillary loops were consistent with the histological features of TMA [28]. However, further studies of kidney histomorphology in children with COVID-19 are still needed to prove the AKI mechanism. Unfortunately, patient 2's family in our study refused autopsy. Clinically, hypocomplementemia $\mathrm{C} 3$ and $\mathrm{C} 4$ were also observed in the two infants of our study (patient 1 and 2), suggesting an activation of the classical complement pathway may underlie the pathogenesis of COVID-19 with AKI. A pattern of tissue damage consistent with complement-mediated microvascular injury in the lung and skin of five individuals with severe COVID-19 was reported recently [27], with more evidence suggesting a role of complement activation in COVID-19 pathophysiology and involvement of important organs [29-31]. A delineation of complement activation in COVID-19 will also shed light on the use of complement inhibitory therapy in COVID-19 patients with AKI.

Medical management in such critically ill COVID-19 patients remains challenging throughout the world and continues to evolve with emerging evidence actively justifying the evidence-based practice. The front-line advanced life support, antimicrobial treatment, and immunomodulatory therapy including steroids, tocilizumab, and plasmapheresis remain empirical. Accumulated evidence from studies in an adult cohort has revealed that early initiation of kidney replacement therapy improved the outcome of critically ill COVID-19 patients, whether AKI is present or not $[13,32]$. The hypothesis of injury from cytokine storm and complement activation in COVID-19 has suggested PE and CKRT be implemented in the management to clear the cytokines and restore the control in complement regulation, which subsequently can reduce inflammation injury to important organs including the kidneys. Our three patients with AKI received PE and CKRT, with evidence showing an improved cytokine profile with these treatments and resulting in recovery in patients 1 and 3. Previous studies have provided strong evidence supporting the extra-renal benefit of CKRT, especially in critical illness with systemic inflammatory response syndrome (SIRS), sepsis, and lifethreatening cytokine storm $[25,33]$. Therefore, the indication for CKRT has been broadened to many ICU patients to address the needs of volume control and clearance of inflammatory cytokines, in addition to the "renal clearance" of small- to mediumsized toxins/waste products [34]. Our case study demonstrated that CKRT did quench the storm of IL-6, the proinflammatory cytokine that might contribute to the mortality of COVID-19, by which it might have ameliorated the severity and improved the chances of survival. Again, clinical trials with a large cohort are needed to confirm this finding.

In conclusion, this is the first study of its kind to report data about AKI as a complication of critically ill children with COVID-19. Cytokine storm and complement activation may play key roles in the development of AKI in children with
COVID-19, which provides a rationale for using kidney replacement therapy to clear inflammation factors and to promote recovery. Multi-center retrospective case-control studies with larger sample size are needed to clarify the underlying etiology of AKI, to direct the prevention, management, and prognosis of the disease.

Acknowledgments The authors thank Francia Fang from the University of Maryland School of Medicine, Baltimore, MD, USA, for the linguistic revisions.

\section{Code availability Not applicable}

Author contributions Xiaowen Wang, Xingfeng Chen, and Jianbo Shao planned the study; Xiaowen Wang wrote the manuscript; Feng Tang, Jian Fang, and Wanjun Luo collected the data; Chang Qi and Hua Sun carried out the statistical analyses; and Han Xiao and Xuehua Peng contributed to the interpretation of the data. All of the authors contributed to, and have approved, the final manuscript.

Funding information All phases of this study were supported by the Natural Science Foundation of Hubei Province (2016CFC728), Key Projects of Scientific Research Program of Wuhan Health Commission (WX16A07), Projects of Healthy Commission of Hubei Province (WJ2019M011), and Projects of Centers for Disease Control and Prevention of Wuhan (WHCDCIRB-K-2020007).

Data availability The authors declare that all data supporting the findings of this study are available within the article and from the corresponding author upon reasonable request.

\section{Compliance with ethical standards}

Conflict of interest The authors declare that they have no conflicts of interest.

Ethics approval The study was approved by the Ethics Committee of Wuhan Children's Hospital (Approval: 2020R003-E01). The Ethics Committee of Tongji Medical College approved this study.

Consent to participate The guardians of the pediatric patients agreed to participate in this study.

\section{References}

1. Chu KH, Tsang WK, Tang CS, Lam MF, Lai FM, To KF, Fung KS, Tang HL, Yan WW, Chan HW, Lai TS, Tong KL, Lai KN (2005) Acute renal impairment in coronavirus-associated severe acute respiratory syndrome. Kidney Int 67:698-705. https://doi. org/10.1111/j.1523-1755.2005.67130.x

2. Li Z, Wu M, Yao J, Guo J, Liao X, Song S, Li J, Duan G, Zhou Y, Wu X, Zhou Z, Wang T, Hu M, Chen X, Fu Y, Lei C, Dong H, Xu C, Hu Y, Han M, Zhou Y, Jia H, Chen X, Yan J (2020) Caution on kidney dysfunctions of COVID-19 patients. medRxiv. https://doi. org/10.1101/2020.02.08.20021212\%JmedRxiv

3. Rismanbaf A, Zarei S (2020) Liver and kidney injuries in COVID19 and their effects on drug therapy; a letter to editor. Arch Acad Emerg Med 8:e17

4. Diao B, Wang C, Wang R, Feng Z, Tan Y, Wang H, Wang C, Liu L, Liu Y, Liu Y, Wang G, Yuan Z, Ren L, Wu Y, Chen Y (2020) 
Human kidney is a target for novel severe acute respiratory syndrome coronavirus 2 (SARS-CoV-2) infection. medRxiv, https:// doi.org/10.1101/2020.03.04.20031120medRxiv

5. Cheng Y, Luo R, Wang K, Zhang M, Wang Z, Dong L, Li J, Yao $\mathrm{Y}, \mathrm{Ge} \mathrm{S}, \mathrm{Xu} \mathrm{G}$ (2020) Kidney disease is associated with in-hospital death of patients with COVID-19. Kidney Int. https://doi.org/10. 1016/j.kint.2020.03.005

6. (2020) The epidemiological characteristics of an outbreak of 2019 novel coronavirus diseases (COVID-19) in China. Zhonghua Liu Xing Bing Xue Za Zhi 41:145-151. https://doi.org/10.3760/cma.j. issn.0254-6450.2020.02.003

7. Lu X, Zhang L, Du H, Zhang J, Li YY, Qu J, Zhang W, Wang Y, Bao S, Li Y, Wu C, Liu H, Liu D, Shao J, Peng X, Yang Y, Liu Z, Xiang Y, Zhang F, Silva RM, Pinkerton KE, Shen K, Xiao H, Xu S, Wong GWK (2020) SARS-CoV-2 infection in children. N Engl J Med. https://doi.org/10.1056/NEJMc2005073

8. Kaddourah A, Basu RK, Bagshaw SM, Goldstein SL (2017) Epidemiology of acute kidney injury in critically ill children and young adults. N Engl J Med 376:11-20. https://doi.org/10.1056/ NEJMoa1611391

9. Kellum JA, Lameire N, Aspelin P, Barsoum RS, Burdmann EA, Goldstein SL, Herzog CA, Joannidis M, Kribben A, Levey AS (2012) Kidney disease: improving global outcomes (KDIGO) acute kidney injury work group. KDIGO clinical practice guideline for acute kidney injury. Kidney Int Suppl 2:1-138

10. Lameire N, Van Biesen W, Vanholder R (2017) Epidemiology of acute kidney injury in children worldwide, including developing countries. Pediatr Nephrol 32:1301-1314. https://doi.org/10.1007/ s00467-016-3433-2

11. Perico L, Benigni A, Remuzzi G (2020) Should COVID-19 concern nephrologists? Why and to what extent? The emerging impasse of angiotensin blockade. Nephron 144:213-221. https://doi. org/10.1159/000507305

12. Yang X, Yu Y, Xu J, Shu H, Xia J, Liu H, Wu Y, Zhang L, Yu Z, Fang M, Yu T, Wang Y, Pan S, Zou X, Yuan S, Shang Y (2020) Clinical course and outcomes of critically ill patients with SARSCoV-2 pneumonia in Wuhan, China: a single-centered, retrospective, observational study. Lancet Respir Med. https://doi.org/10. 1016/s2213-2600(20)30079-5

13. Yang XH, Sun RH, Chen DC (2020) Diagnosis and treatment of COVID-19: acute kidney injury cannot be ignored. Zhonghua Yi Xue Za Zhi 100:E017. https://doi.org/10.3760/cma.j.cn11213720200229-00520

14. Sutherland SM, Kwiatkowski DM (2017) Acute kidney injury in children. Adv Chronic Kidney Dis 24:380-387. https://doi.org/10. 1053/j.ackd.2017.09.007

15. Xu X, Nie S, Zhang A, Mao J, Liu HP, Xia H, Xu H, Liu Z, Feng S, Zhou W, Liu X, Yang Y, Tao Y, Feng Y, Chen C, Wang M, Zha Y, Feng JH, Li Q, Ge S, Chen J, He Y, Teng S, Hao C, Liu BC, Tang Y, He W, He P, Hou FF (2018) Acute kidney injury among hospitalized children in China. Clin J Am Soc Nephrol 13:1791-1800. https://doi.org/10.2215/CJN.00800118

16. Benoit SW, Devarajan P (2018) Acute kidney injury: emerging pharmacotherapies in current clinical trials. Pediatr Nephrol 33: 779-787. https://doi.org/10.1007/s00467-017-3695-3

17. Ciccia E, Devarajan P (2017) Pediatric acute kidney injury: prevalence, impact and management challenges. Int J Nephrol Renovasc Dis 10:77-84. https://doi.org/10.2147/IJNRD.S103785

18. Xu X, Nie S, Zhang A, Jianhua M, Liu HP, Xia H, Xu H, Liu Z, Feng S, Zhou W, Liu X, Yang Y, Tao Y, Feng Y, Chen C, Wang M, Zha Y, Feng JH, Li Q, Ge S, Chen J, He Y, Teng S, Hao C, Liu BC, Tang Y, Wang LJ, Qi JL, He W, He P, Liu Y, Hou FF (2018) A new criterion for pediatric AKI based on the reference change value of serum creatinine. J Am Soc Nephrol 29:2432-2442. https://doi. org/10.1681/ASN.2018010090
19. Deng YY, Zheng Y, Cai GY, Chen XM, Hong Q (2020) Single-cell RNA sequencing data suggest a role for angiotensin-converting enzyme 2 in kidney impairment in patients infected with 2019nCoV. Chin Med J. https://doi.org/10.1097/cm9. 0000000000000783

20. Chen Y, Guo Y, Pan Y, Zhao ZJ (2020) Structure analysis of the receptor binding of 2019-nCoV. Biochem Biophys Res Commun. https://doi.org/10.1016/j.bbrc.2020.02.071

21. Qi F, Qian S, Zhang S, Zhang Z (2020) Single cell RNA sequencing of 13 human tissues identify cell types and receptors of human coronaviruses. Biochem Biophys Res Commun. https://doi.org/ 10.1016/j.bbrc.2020.03.044

22. Shang J, Ye G, Shi K, Wan Y, Luo C, Aihara H, Geng Q, Auerbach A, Li F (2020) Structural basis of receptor recognition by SARSCoV-2. Nature. https://doi.org/10.1038/s41586-020-2179-y

23. Tveito K (2020) Cytokine storms in COVID-19 cases? Tidsskr Nor Laegeforen 140. https://doi.org/10.4045/tidsskr.20.0239

24. Pedersen SF, Ho YC (2020) SARS-CoV-2: a storm is raging. J Clin Invest. https://doi.org/10.1172/jci137647

25. Ronco C, Reis T (2020) Kidney involvement in COVID-19 and rationale for extracorporeal therapies. Nat Rev Nephrol. https://doi. org/10.1038/s41581-020-0284-7

26. Wu C, Chen X, Cai Y, Xia J, Zhou X, Xu S, Huang H, Zhang L, Zhou X, Du C, Zhang Y, Song J, Wang S, Chao Y, Yang Z, Xu J, Zhou X, Chen D, Xiong W, Xu L, Zhou F, Jiang J, Bai C, Zheng J, Song Y (2020) Risk factors associated with acute respiratory distress syndrome and death in patients with coronavirus disease 2019 pneumonia in Wuhan, China. JAMA Intern Med. https://doi.org/10. 1001/jamainternmed.2020.0994

27. Magro C, Mulvey JJ, Berlin D, Nuovo G, Salvatore S, Harp J, Baxter-Stoltzfus A, Laurence J (2020) Complement associated microvascular injury and thrombosis in the pathogenesis of severe COVID-19 infection: a report of five cases. Transl Res 220:1-13. https://doi.org/10.1016/j.trsl.2020.04.007

28. Su H, Yang M, Wan C, Yi L-X, Tang F, Zhu H-Y, Yi F, Yang H-C, Fogo AB, Nie X, Zhang C (2020) Renal histopathological analysis of 26 postmortem findings of patients with COVID-19 in China. Kidney Int. https://doi.org/10.1016/j.kint.2020.04.003

29. Mulay SR, Holderied A, Kumar SV, Anders HJ (2016) Targeting inflammation in so-called acute kidney injury. Semin Nephrol 36: 17-30. https://doi.org/10.1016/j.semnephrol.2016.01.006

30. McCullough JW, Renner B, Thurman JM (2013) The role of the complement system in acute kidney injury. Semin Nephrol 33:543556. https://doi.org/10.1016/j.semnephrol.2013.08.005

31. Zilberman-Itskovich S, Abu-Hamad R, Stark M, Efrati S (2019) Effect of anti-C5 antibody on recuperation from ischemia/ reperfusion-induced acute kidney injury. Ren Fail 41:967-975. https://doi.org/10.1080/0886022x.2019.1677248

32. Ma J, Xia P, Zhou Y, Liu Z, Zhou X, Wang J, Li T, Yan X, Chen L, Zhang S, Qin Y, Li X (2020) Potential effect of blood purification therapy in reducing cytokine storm as a late complication of severe COVID-19. Clin Immunol 108408. https://doi.org/10.1016/j.clim. 2020.108408

33. Fayad AI, Buamscha DG, Ciapponi A (2016) Intensity of continuous renal replacement therapy for acute kidney injury. Cochrane Database Syst Rev 10:CD010613. https://doi.org/10.1002/ 14651858.CD010613.pub2

34. Zhang J, Tian J, Sun H, Digvijay K, Neri M, Bhargava V, Yin Y, Ronco C (2018) How does continuous renal replacement therapy affect septic acute kidney injury? Blood Purif 46:326-331. https:// doi.org/10.1159/000492026

Publisher's note Springer Nature remains neutral with regard to jurisdictional claims in published maps and institutional affiliations. 